\title{
Correction to: Plasma Fibrinogen Is a Natural Deterrent to Amyloid $\beta$-Induced Platelet Activation and Neuronal Toxicity
}

Vijay K. Sonkar ${ }^{1,4,5}$, Paresh P. Kulkarni ${ }^{1}$, Susheel N. Chaurasia' ${ }^{1}$, Ayusman Dash ${ }^{2}$, Abhishek Jauhari ${ }^{3}$, Devendra Parmar ${ }^{3}$, Sanjay Yadav ${ }^{3}$ and Debabrata Dash ${ }^{1^{*}}$

Correction to: Mol Med 22:224-232, 2016

DOI 10.2119/molmed.2016.00003

Following publication of the original article (Sonkar et al. 2016), the author reported an error in Fig. 1. The correct version of Fig. 1 is as follows:

\section{Author details}

'Department of Biochemistry, Institute of Medical Sciences, Banaras Hindu University, Varanasi, Uttar Pradesh, India. ${ }^{2}$ Indian Institute of Science Education and Research, Kolkata, India. ${ }^{3}$ Developmental Toxicology Division, Indian Institute of Toxicological Research, Lucknow, Uttar Pradesh, India.

${ }^{4}$ Present address: Department of Biochemistry, School of Life Sciences, Central University of Rajasthan, Bandrasindri, Kishangarh, Ajmer, India. ${ }^{5}$ Department of Internal Medicine, University of lowa, lowa City, USA.

Published online: 30 July 2019

\section{Reference}

Sonkar VK, et al. Plasma fibrinogen is a natural deterrent to amyloid $\beta$-induced platelet activation and neuronal toxicity. Mol Med. 2016;22:224-32. https:// doi.org/10.2119/molmed.2016.00003. 
A

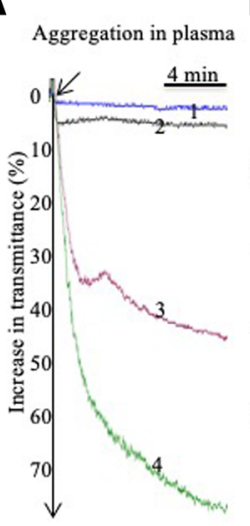

B

Aggregation and ATP release
in the presence of fibrinogen
or BSA

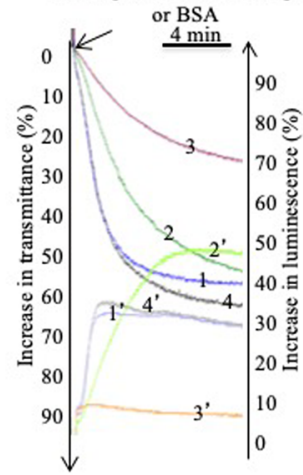

aggregation $\mathbf{n}$ Secretion

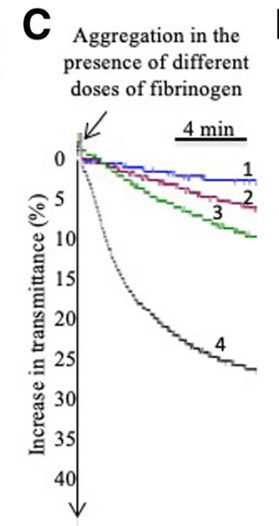

D Aggregation induced by different doses of $A \beta$ in the presence of fibrinogen

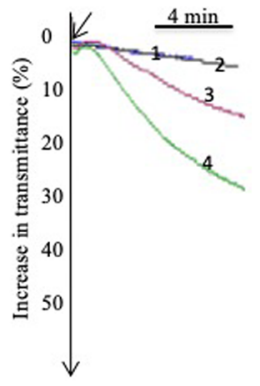

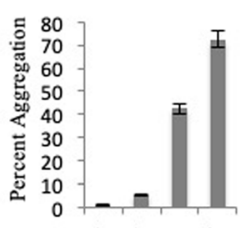

$\left.\begin{array}{r}70 \\ 60 \\ 50 \\ \hline 3 \\ 40 \\ 30 \\ 20 \\ 10 \\ 0\end{array}\right]$
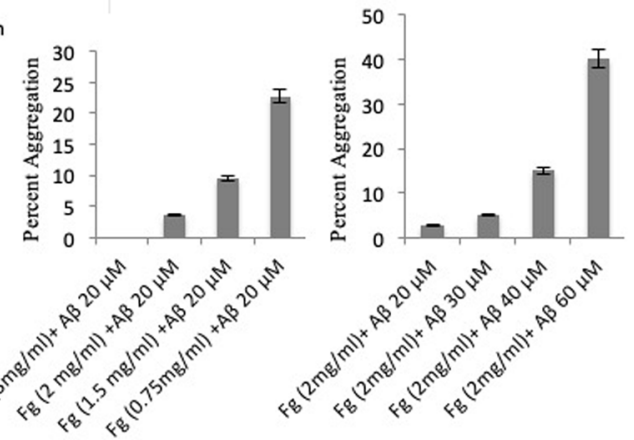

E

P-selectin exposure

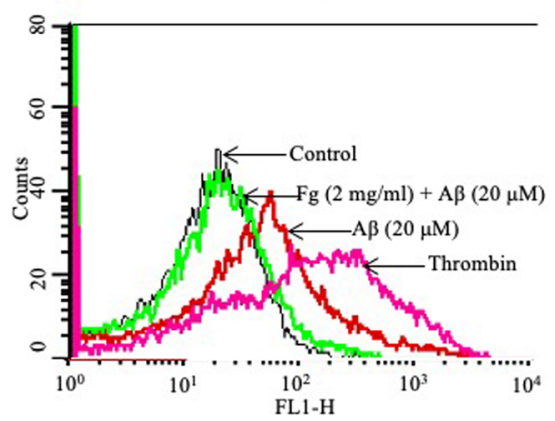

$\mathbf{F}$
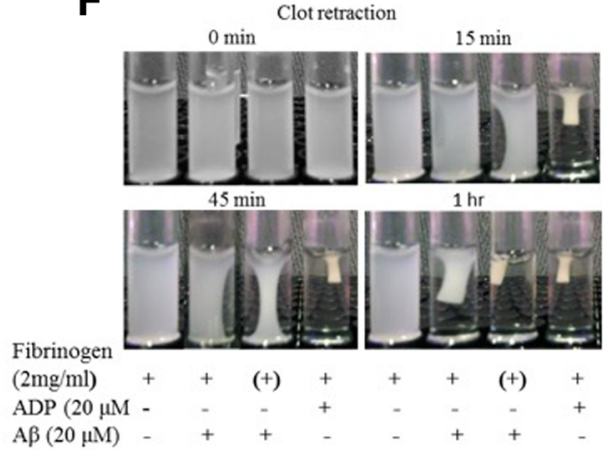

$(+)$ indicates addition of $A \beta$ prior to fibrinogen

Fig. 1 Effect of fibrinogen on $A \beta_{25-35}$-induced platelet activation. a Tracings 1, 2, 3 and 4 represent platelet aggregation in $P R P$ induced by $A \beta_{25-35}(20$ and $50 \mu \mathrm{mol} / \mathrm{L}), \operatorname{ADP}(20 \mu \mathrm{mol} / \mathrm{L})$ and collagen $(10 \mu \mathrm{g} / \mathrm{mL})$, respectively. The corresponding bar diagram is shown in the lower panel. b Tracings $1-4$ represent aggregation, and tracings $1^{\prime}-4^{\prime}$ represent corresponding dense granule secretion in washed platelets stimulated with either thrombin $(1 \mathrm{U} /$ $\mathrm{mL}$; tracings 2 and 2') or $A \beta_{25-35}(20 \mu \mathrm{mol} / \mathrm{L}$; tracings 1, 1', 3, 3', 4 and 4'). Tracings 3 and 3' represent platelets pretreated with fibrinogen ( $2 \mathrm{mg} / \mathrm{mL})$, whereas tracings 4 and $4^{\prime}$ represent platelets pretreated with BSA ( $\left.2 \mathrm{mg} / \mathrm{mL}\right)$. Corresponding bar diagram is shown in the lower panel. c Tracings 1, 2 , 3 and 4 represent aggregation of washed platelets induced by $A \beta_{25-35}(20 \mu \mathrm{mol} / \mathrm{L})$ in the presence of $3,2,1.5$ and $0.75 \mathrm{mg} / \mathrm{mL}$ fibrinogen, respectively. Corresponding bar diagram is shown in the lower panel. d Tracings 1, 2, 3 and 4 represent aggregation of washed platelets induced by $A \beta_{25-35}$ (20, 30,40 and $60 \mu \mathrm{mol} / \mathrm{L}$, respectively) in the presence of fibrinogen $(2 \mathrm{mg} / \mathrm{mL})$. Corresponding bar diagram is shown in the lower panel. e Flow cytometric analysis of expression of P-selectin on surface of platelets treated with different reagents and agonists as indicated. $\mathbf{f}$ Retraction of fibrin clot by platelets stimulated with either $A \beta_{25-35}(20 \mu \mathrm{mol} / \mathrm{L})$ or $A D P(20 \mu \mathrm{mol} / \mathrm{L})$ in presence of fibrinogen $(2 \mathrm{mg} / \mathrm{mL})$ added either before or after exposure to agonists as indicated 